\title{
Analysis on the Upgrading and Development of Chinese Manufacturing Industry Based on Green Technology Innovation
}

\author{
Xiaohui An \\ School of Management, Tianjin University of Technology, Tianjin, 300384, China
}

Keywords: New industrial revolution, Low carbon development, Green technology innovation, Manufacturing upgrading and transformation.

\begin{abstract}
To cope with the challenge of the new industrial revolution and the new situation of manufacturing industry competition at home and abroad, the "made in China 2025" strategy proposed by China will closely link carbon emission reduction of manufacturing industry with manufacturing power, and prosper China through manufacturing. The transformation to green and innovation of industry will become the endogenous driving force for low-carbon development of Chinese manufacturing industry. Green technology innovation has become the key link in the development of green innovation of manufacturing industry. This paper analyzed the basic situation of the current green technology innovation, and the driving factors of green technology innovation of the enterprise. On this basis, it analyzed the development path of Chinese manufacturing industry under the background of the new industrial revolution.
\end{abstract}

\section{Introduction}

With the proposal of the five development concepts during the fifth plenary session of the 18th CPC central committee, the concept of green development was highlighted during the 13th five-year plan period. The concept of green development refers to the harmonious development of people and nature, economic and social environment, and the idea of this concept has played a role in promoting and supporting the economic development of our country.

The so-called green development concept refers to the harmonious development of people and nature, economic and social environment, and the proposal of this concept has played a role in promoting and supporting the economic development of our country. At present, as a pillar industry of China's national economy, the manufacturing industry has played a huge role in the development of economy and the construction of national economy of our country. However, with the increasing consumption of manufacturing resources, and the increasingly prominent environmental pollution problems, the manufacturing industry of our country faces significant challenges. The world's economy has been developing continuously, since Germany formally put forward the "industry 4.0" development strategy, countries of the world have invested in the construction of intelligent manufacturing one after another. However, Chinese manufacturing is in a period of slow development, and the traditional manufacturing industry faces the threat of various technological transformations. Therefore, in the context of the new industrial revolution and under the guidance of green development concept, how to realize the transformation and upgrading of manufacturing industry is particularly important. To cope with the new situation of manufacturing industry competition at home and abroad and the challenge of new industrial revolution, China has put forward "made in China 2025" the Chinese version of industry 4.0 plan that aims to provide an action guide for the development of China's manufacturing transformation and upgrading.

Chinese "industry 4.0" plan proposes higher requirements to the green technology innovation of manufacturing industry, because it is one of the key contents to realize the green innovation development of manufacturing industry. This paper first analyzes the basic situation of green technology innovation, clarifies the driving factors of green technological innovation of enterprises, on the basis of the present situation of Chinese manufacturing industry, this paper discusses the upgrading path of Chinese manufacturing based on green technology. 


\section{Green technology innovation}

\subsection{Introduction of green technology innovation}

The so-called green technological innovation in essence is the floorboard of thought, behavior, technology, method and in all aspects. To take the environment protection as the center, it inculcates the enterprise the concept of green development and green management, the aim of optimizing the ecological benefit and technical level is emphasized in the process of obtaining economic benefits [1]. Compared with the traditional technology innovation, green technology innovation provides guarantee for enterprises to realize sustainable development, and puts forward higher requirements on the technological innovation of enterprises in environmental protection. Green technology requires companies to fully consider production technologies that damage environment such as pollutant emissions in the process of production when choosing production technology, aims at making the choice of production technology which is conducive to environmental protection and ecological balance. However, with the economy develops and social diversity becomes more and more serious, different people have different understandings of the meaning of green technology. It's thought that green technology is the sum of environmental protection technology and ecological technology, green technology is the production technology that can achieve environmental protection and resource conservation. In addition, some people think that green technology is mainly focused on product design technology, fusing environmental protection features with products, and integrating products with environmental awareness. Others believe that green technology is a contribution to the welfare of society and the development of human healthy civilization.

Combining with the above meanings, the essence of green technology is summarized as follows:

(1) Firstly, the green technology is built around environmental protection. No matter it is the green technology of environmental protection or the green awareness that fused into the products, it is built around green production and green manufacturing in order to realize the basic responsibility of protecting environment while developing the enterprise economy, the harmonious development of man and nature finally and ensure ecological balance.

(2) Secondly, the green technology is not only a production technology, but a system technology of the whole production cycle of the early design to the recovery and utilization of the later period of the total product. It is a kind of thought and consciousness that runs through the whole process of product production and utilization.

Green technology innovation is to realize innovation based on the contents of above green technology, it is a new term newly developed recent years. It is not only the product of economic development but also the technological need to protect the environment. Green technology innovation was initially thought to be merely an innovation in environmental protection resource investment, but with the progress of the times, this understanding has appeared to be weak. It is impossible to realize the essence of green technology innovation without the investment of green technology. Therefore, green technology innovation should take environmental protection to achieve sustainable development as the goal, integrate green consciousness into the contents of green technology, to realize the multi-objectives optimization of economic development, environmental protection and social benefits [2].

\subsection{The driving factors of green technology innovation}

The development of green technology innovation is not only the demand of the society but also the sustainable development demand of the enterprise itself. The driving factors of green technology innovation are summarized as follows:

(1) Firstly, it is the need of economic development and the constraint of government system. With the advent of the era of "Industry 4.0", manufacturing enterprises are forced to meet the requirements of development in this era, the government departments put forward guidelines for manufacturing transformation and upgrading for the change in this era and require manufacturing enterprises to improve production mode under the regulation of environment, legal system and other policies. Under the constraints of government system, enterprises have to innovate and improve their 
technology so as to ensure the orderly development under the general environment. (2) Secondly, the self-consciousness innovation within the enterprise. The resources and organizational elements of enterprises are the basis of green technology innovation. These resources include the green oriented consciousness of the enterprise, namely whether the enterprise have the consciousness of green development and environmental protection, whether the enterprise set up the interior environmental protection system and the consciousness whether the enterprise can take the external environment responsibilities. In addition, the green technology ability of the enterprise, that is the ability of the enterprise to independently develop and build green management system, as well as the ability to implement all kinds of green management strategies. These internal resources drive enterprises to implement green technological innovation to a great extent. (3) Thirdly, the new theory of market economy and environment-market theory show that green technology innovation not only needs to reduce environmental pollution indicators but also brings benefits to customers. Under the constraint of institutional environment, enterprises hope to innovate in green technology, realize product differentiation design, and gain the competitive advantage. However, if the enterprise only reduces the environmental pollution, do not bring direct benefits for the customers, the customer is impossible to have a high recognition to the products, so in order to adapt to the current institutional environment, the enterprise must carry out the green technology innovation to gain market competitiveness.

\section{Analysis on problems and development path faced by Chinese manufacturing upgrading.}

\subsection{The meaning of industry upgrading}

Industry upgrading has always been an important content of economic development, especially as countries have promoted the economic rise with industry upgrading strategies, industry upgrading has become an important part of Chinese economic development. As to the connotation of industry upgrading, there is no unified opinion so far, which needs to be introduced in two aspects: micro level and macro level.

Firstly, on the macro level, the so-called industry upgrading is the process that the first industry upgraded to secondary industry or tertiary industry, which is the change of industrial structure. Secondly, on the micro level, industrial upgrading refers to the gradually deepening process of industry, gradually transforming the production factors from fixed resources and labors to high quality elements such as technology, capital and so on, realizing the process of transforming the low output value to high output value [3].

At present, industrial upgrading and development of our country is facing many problems. First, many industries in China are at the low end of the value chain. Since China joined the WTO organization, despite the continuous development of economic trade and the growing level of trade exports, most industries in China are at the low end of the value chain, lacking of the core technical elements. With the gradual disappearance of "demographic dividend", industrial upgrading of our country is facing a bigger challenge. In addition, although Chinese economy has made great progress in recent years, environmental pollution, environmental damage and other problems frequently occurred. Although the GDP of our country is three to four times than that of other countries, the emission of environmental pollutants is far higher than that of developed countries. As the issue of environment deteriorates, ecological imbalance is becoming more and more prominent, the industrial upgrading must include environmental protection and ecological balance. Industry upgrading should realize some basic meanings of value oriented type, resource oriented type and environmental oriented type of industrial upgrading. The value oriented type refers to the continuous deepening of the reform in the production process to realize the value enhancement; resource oriented type refers to reduce energy consumption of the products and improve energy efficiency during product input. Environmental oriented type is to fully integrate environmental protection into industrial upgrading, aiming at achieving sustainable development and reducing pollutant emission. These contents of industrial upgrading are also the key contents that Chinese manufacturing industry needs to undertake to upgrade and develop. 


\subsection{The basic characteristics of Chinese manufacturing industry and the difficulties it faces.}

As the support industry of China's economic development, manufacturing industry has a long history. Traditional manufacturing industry has the characteristics of high resource consumption, high pollution, low efficiency and so on. It is precisely because of these characteristics that Chinese manufacturing industry faces inevitable difficulties:

(1) First, the advantage of low cost no longer exists

In previous years, due to the advantage of population, China has the advantage of low labor cost and resource cost, but as demographic dividend of our country gradually disappeared, human resource cost was rising gradually, the cost of hiring increased year by year, and manufacturing industry needed a large number of labor resources, so the cost could do a lot of drawbacks [4]. At the same time, with the serious shortage of resources, the shortage of manufacturing resources leaded to the increasing cost of resources. As a result, manufacturing lost market competitiveness gradually.

(2) Resources and energy consume excessively and environment was polluted seriously.

Manufacturing is a production industry that transforms raw materials into the actual products, so the resources needed are basically primordial natural resources, and resources consumed are most the high carbon energy, which result in the shortage of resources and environmental pollution. These problems are prominent.

(3) The internal environment of the industry has gradually deteriorated.

With the outbreak of financial crisis in past few years, it had brought serious consequences for the manufacturing industry: foreign economies had been hit hard which leaded to a sharp decline in exports of manufacturing products, the economy was seriously damaged. Second, in order to protect their own resources, all countries raised the proportion of import and export taxes sharply, which resulted in higher costs and a sharp decline in profits.

\subsection{Analysis on the upgrading and developing path of Chinese manufacturing under the background of green technology innovation.}

After analyzing the basic characteristics of green technology innovation, the connotation of industrial upgrading, and the difficulties the Chinese manufacturing industry is facing, this paper considers the upgrading and developing path of Chinese manufacturing industry based on green technology innovation is:

(1) Promote the development of Chinese manufacturing industry with green technology innovation.

The innovation of green technology is the driving force for upgrading and developing of Chinese manufacturing industry, which requires the government to improve the guarantee system of technological innovation and make incentive policies to create a favorable technological innovation environment for manufacturing enterprises and provide a good technical innovation platform for enterprises to strengthen the joint work with all technology research institutes [5].

(2) Relying on the new Internet technology to improve the innovation ability of manufacturing industry.

At present, the sustainable technology develops rapidly, and with the continuous emergence of computer technologies such as big data and cloud services, it has brought great development advantages to the upgrading of manufacturing enterprises. The new Internet thought added with big data technology can realize digital industrial manufacturing and comply with the development demand of "Industry 4.0".

(3) The enterprise itself should construct a reasonable system of technological innovation.

The enterprise should increase the training of talents, introduce innovative talents of science and technology, and build a talent pool to ensure the talent demand of itself. At the same time, manufacturing enterprises should pay attention to the improvement of their own innovation technology, combine with the advantages of internal and external resources and realize the innovation-oriented upgrading of manufacturing enterprise. 


\section{Conclusions}

In this paper, we analyze the basic overview of the green technology innovation under the background of contemporary economic development. Starting from the definition of green technology, we analyze the basic contents of green technology innovation, and the driving factors of green technology innovation from the internal and external perspectives. At last, we analyze the connotation of industry upgrading on the basis of the basic characteristics of Chinese manufacturing industry and the current development status of manufacturing industry, and the upgrading and developing path of Chinese under the background of green technology innovation.

\section{Acknowledgements}

This research was financially supported by the Tianjin science and technology project: "Research on the green innovation development path of traditional manufacturing industry of Tianjin under the background of new industry" (No. 15zlzlzlzf00160); The humanity and social science research project of Tianjin higher school "Study on carbon productivity measurement and carbon reduction path in Tianjin" (No.20132109).

\section{References}

[1] Chen Guoyu, Research on green technology innovation, Nanchang university, 2008

[2] Sui Jun, Bi Kexin, Yang Chaojun, Liu Gang, the influence factors of innovation performance of manufacturing green innovation system -- based on the research of technology transfer angle of transnational corporation, Scientific research. 2015,33(03):440-448.

[3] Zhu Weiping, Chen Lin, Research on the connotation and model of industrial upgrading -- taking Guangdong industrial upgrading for example, Economist, 2011, (02): 60-66.

[4] Yuan Yijun, Dai Ning, the upgrading and developing path of Chinese manufacturing industry based on green technology innovation, Technology and management, 2015, 19(01): 8 to 15.

[5] Du Peng, Research on the upgrading of Chinese manufacturing industry, Wuhan university, 2012.

[6] Li Ruobing, Wei Ailing, Peng Jing, Cheng Min, Research on promoting the upgrading of manufacturing industry by technological innovation, Modern business and commerce industry,2017, (27): 3-4. 